\title{
LAS ARRAS EN EL DERECHO JUSTINIANEO*
}

\author{
Patricio-Ignacio Carvajal R. ${ }^{* *}$
}

\begin{abstract}
SUMARIO: Este trabajo intenta explicar cómo las "arras penitenciales" son una innovación justinianea que se aparta de los sistemas contractuales, como el romano clásico y los actuales, basados en el principio del consensualismo. A partir de este desarrollo histórico se comprenden muchas de sus dificultades dogmáticas hoy.
\end{abstract}

Palabras clave: arras, compraventa, Código de Justiniano, Instituciones de Justiniano, Código Civil, garantía, caución, arrepentimiento, penitencial, Derecho Romano, Derechos Griegos.

\begin{abstract}
This work try to explain how the "regrets pledges" became a justinianean innovation, separated from contract law systems, in classic Rome and even in our days, founded on the principle of consensualism. From this historical development it's possible to understand many of its dogmatical difficulties today.
\end{abstract}

Key words: down payments, sale, Justinian Code, Justinian Institutiones, Civil Code, warranty, bond, repentace, penalties, Roman Law, Greek Law.

\section{LAS FUNCIONES DE LAS ARRAS. CUESTIONES GENERALES ${ }^{1}$}

La cuestión de las arras no solo tiene importancia en materia de compraventa ${ }^{2}-$ si bien aquí se encuentra su núcleo histórico-, sino que, de manera general, en las garantías dentro del derecho de obligaciones, tal como lo tratan los códigos más modernos ${ }^{3}$.

La entrega de arras, es decir, la entrega de dinero u otros objetos de valor con ocasión de la celebración o ejecución de un contrato ${ }^{4}$, puede cumplir diversas funciones:

(1) Arras confirmatorias: ${ }^{5}$ se trata de las arras dadas simplemente como prueba o "señal" de que ha tenido lugar una convención vinculante por sí misma. Las arras

\footnotetext{
* El texto corresponde a la ponencia presentada, con el mismo título, en el XV Congreso Latinoamericano de Derecho Romano, celebrado en la ciudad de Morelia, México, los días 16, 17 y 18 de agosto del 2006.

** Pontificia Universidad Católica de Chile.

1 Vid., para todo lo señalado en el presente trabajo, CARVAjAL (2001); (2003); (2005).

${ }^{2}$ Ej. Code Civil, art. 1590, sec. III, Tit. VI, libro III, "De la promesa de venta y las arras"; C.C. español, Tit. IV, cap. I, "Del contrato de compra y venta".

${ }^{3}$ Ej. Ya el BGB, $\$ \$ 336$ a 338, correspondientes al libro II, relativo al Derecho de obligaciones (Recht der Schuldverhältnisse), trata las arras (Draufgabe, Draufgeld) entre las cuestiones relativas a las penas convencionales (Titel 4. Draufgabe. Vertragsstrafe). Otro tanto, puede decirse del Código Suizo de las Obligaciones, arts. 160 a 163. Por su parte, el Codice civile de 1942 trata el tema a continuación de la cláusula penal, art. 1385, rompiendo la tradición histórica.

${ }^{4}$ Cfr. Ulp., 32 ad Ed., D. 19, 1, 11, 6.

5 El término fue acuñado por la escuela alemana y holandesa del siglo XVI. El carácter confirmatorio otorgado por el Derecho común imponía la consecuencia de que la pena arral en nada obstaba para el íntegro resarcimiento del daño. Cfr. FACHINeI (1669) cap. 28. En contra de esta opinión, considerando
} 
confirmatorias tienen, a su vez, una doble vertiente que se aprecia, por ejemplo, en el Código de Bello, art. 1805: "Si... se dieren arras como parte del precio o como señal de quedar convenidos los contratantes, quedará perfecta la venta". Por un lado están las arras confirmatorias "de simple prueba" y, del otro, las arras confirmatorias "de ejecución del contrato"; mientras las segundas consisten siempre en dinero, las primeras pueden consistir en algún otro objeto de valor. Las arras confirmatorias-parte del precio representan el comienzo de ejecución del contrato, debiendo calificárselas primordialmente, en consecuencia, como pago $^{6}$. Son ejemplo de este tipo de arras, además de las del Código Civil chileno, las del Código de Comercio de este mismo país ${ }^{7}$, del Código de Comercio mexicano $^{8}$, del Código de Comercio argentino ${ }^{9}$ y del Código de Comercio español ${ }^{10}$.

que la pena arral limitaba la pretensión de resarcimiento: VInNiUS (1767) pp. 741 ss. Con todo, para la dogmática y la jurisprudencia modernas debe tenerse en cuenta que sea cual sea la función desempeñada por las arras, estas siempre cumplen con la función confirmatoria. Esto último, en el sentido de que las arras siempre dejan en evidendencia que entre las partes existe un negocio, si bien este puede estar jurídicamente ya más o ya menos afinado. Vid. Albaladejo (1996) pp. 10 y 11; SAMPer (en prensa).

6 "El carácter confirmatorio del contrato de la cantidad de dos millones de pesetas entregada por los representantes de los compradores al vendedor al momento de la firma del documento privado de 8 de septiembre de 1983, resulta de los propios términos de la estipulación segunda en la que, después de fijar el precio de la venta en treinta millones quinientas mil pesetas, se dice que 'a cuenta y como señal de dicho precio, los apoderados de los compradores entregan en este acto al vendedor dos millones de pesetas, y lo restante se lo entregarán'..., sin que ni en esa estipulación ni en las restantes que conforman el contenido del contrato resulte manifestada la naturaleza penitencial de las arras que se propugna en el motivo, al no atribuirse a las partes, recíproca ni unilateralmente, la facultad de apartarse del contenido con las consecuencias que establece el citado artículo 1454 del Código Civil que, por ello, no resulta infringido por la Sala sentenciadora de instancia sino que aplica correctamente el mismo y asi como la doctrina al respecto emanada de esta Sala" STS (1997).

7 En el C. Com. chileno, el carácter confirmatorio es la norma general. Art. 107: "La dación de arras no importa reserva del derecho de arrepentirse del contrato ya perfecto, a menos que se hubiere estipulado lo contrario". En consecuencia, no se altera para nada el natural iter del contrato ni los remedios para su incumplimiento, tal como lo indica el artículo 108, que señala: "La oferta de abandonar las arras o de devolverlas dobladas no exonera a los contratantes de la obligación de cumplir el contrato perfecto o de pagar daños y perjuicios". De tal manera que nada justifica la retención de las arras una vez cumplidas las prestaciones, ya in natura ya por equivalente, como lo reza el artículo 109: "Cumplido el contrato o pagada una indemnización, las arras serán devueltas, sea cual fuere la parte que hubiere rehusado el cumplimiento del contrato".

${ }^{8}$ C. Com. mexicano, artículo 381: "Salvo pacto en contrario, las cantidades que con el carácter de arras se entreguen en las ventas mercantiles, se reputarán dadas a cuenta de precio".

9 C. Com. argentino, artículo 475, inciso primero: "Las cantidades que con el nombre de señal o arras se suelen entregar en las ventas, se entiende siempre que lo han sido por cuenta del precio y en signo de ratificación del contrato, sin que pueda ninguna de las partes retractarse, perdiendo las arras. Cuando el vendedor y el comprador convengan en que, mediante la pérdida de las arras o cantidad anticipada, les sea lícito arrepentirse y dejar de cumplir lo contratado, deberán expresarlo asi por cláusula especial del contrato".

${ }^{10}$ C. Com. español, art. 343: "las cantidades que, por vía de señal, se entreguen en las ventas mercantiles se reputarán siempre dadas a cuenta del precio y en prueba de la ratificación del contrato, salvo pacto en contrario". Aunque el Código Civil español únicamente discipline las arras penitenciales (que se verán a continuación), esto no ha impedido que, entre otros sentidos, la jurisprudencia haya reconocido la existencia y validez de las arras meramente confirmatorias también en materia civil. A manera de ejemplo: "Las arras confirmatorias actúan en el ámbito obligacional de los contratos con fuerza vinculante que no faculta, por tanto, para resolver las obligaciones contraidas y que normalmente se corresponden con las entregas o anticipos del precio a cuenta (Sentencia de 25 marzo 1995); en cambio las arras penitenciales, contempladas en el 
(2) Arras penitenciales: son aquellas que acompañan un contrato ya perfecto ${ }^{11}, y$ por tanto vinculante, en virtud de las cuales cualquiera de las partes puede retractarse del contrato mediante la pérdida o restitución agravada de lo que se dio o recibió en calidad de arras. En este caso, toman la forma aproximada de la cláusula penal ${ }^{12}$-en cuanto cumplen una función indemnizatoria o, lo mismo, satisfactoria-, a favor de la parte que ha perseverado en el contrato ${ }^{13}$. Encontramos estas arras, por ejemplo, en el Código Civil chileno ${ }^{14}$, el peruano ${ }^{15}$, el argentino ${ }^{16}$ y el español ${ }^{17}$.

(3) Arras penales: en sus consecuencias indemnizatorias son similares a las arras penitenciales, pero la pena en este caso deja incólume la necesidad de dar cumplimiento al contrato al que acceden las arras; es decir, las arras penales no permiten la retractación de las partes. De alguna manera, entonces, se acercan a la cláusula penal-multa ${ }^{18}$. Más

artículo 1454 del Código Civil, autorizan a las partes, por mediar concierto libremente convenido, conforme a la libertad contractual consagrada en el artículo 1255, a desistir del negocio a su arbitrio, pero cumpliendo con la sanción pecuniaria que el precepto autoriza" STS (1999). Vid. AlBALADEJO (1996).

${ }^{11}$ Con todo, al menos en cuanto al origen de esta denominación la situación fue completamente distinta. La pandactística alemana del siglo XIX empleó la terminología "arras penitenciales" como contrapuesta a las arras confirmatorias; y, por consiguiente, las arras penitenciales estaban vinculadas a las arras pacto imperfecto data. Vid. AFONSO (1995) p. 59.

12 La doctrina italiana denomina las arras: "cláusula penal impropia". Vid. TRABUCCHI (1990) p. 702.

13 "En orden a la naturaleza del pacto de arras, la jurisprudencia de la Sala viene admitiendo la existencia de las siguientes clases: a) Penitenciales, que son las que parece contemplar el artículo 1454 del Código Civil, concebidas a la manera de multa o pena, correlativa al derecho de las partes de desistir, a su arbitrio, del contrato" STS (1994).

14 C. C. chileno, art. 1803: "Si se vende con arras, esto es, dando una cosa en prenda de la celebración o ejecución del contrato, se entiende que cada uno de los contratantes podrá retractarse; el que ha dado las arras, perdiéndolas; y el que las ha recibido, restituyéndolas dobladas".

15 C. C. peruano, arts. 1477, 1478, 1479. En efecto, en el Título XIII, "Arras Confirmatorias", establece, siguiendo la estructura que revisamos, el carácter probatorio de este instituto (art. 1477), unido, a la vez, con la facultad de retractación o ius poenitendi (art. 1478). Por esta razón, las arras allí tratadas parecen ser, en realidad, más que arras confirmatorias (como lo anuncia su título), arras penitenciales. En ellas, queda al arbitrio de la parte cumplidora, a favor de quien se establece la institución, la elección entre la utilización de esta vía y las propias de la condición resolutoria tácita (art. 1479), lo que pareciera acentuar que el efecto indemnizatorio de las arras penitenciales se acerca a la cláusula penal; opción legislativa claramente adoptada por el C. C. argentino (art. 1189).

16 C. Com. argentino, art. 475, inciso $2^{\circ}$; C. C. argentino, art. 1189: "Si en el instrumento público se hubiese estipulado una cláusula penal, o el contrato fuese hecho dándose arras, la indemnización de las pérdidas e intereses consistirá en el pago de la pena, y en el segundo en la pérdida de la señal, o su restitución con otro tanto".

17 C. C. español, art. 1454: "Si hubiesen mediado arras o señal en el contrato de compra y venta, podrá rescindirse el contrato allanándose el comprador a perderlas, o el vendedor a devolverlas duplicadas".

18 "...penales, que funcionan de modo similar a la cláusula penal del art. 1154, como resarcimiento en este supuesto anticipado, para el caso de incumplimiento y siempre con la posibilidad de reclamar ese estricto cumplimiento de la obligación pactada" STS (1995). Los Principios del Derecho Europeo de Contratos, en la ilustración 2 de su comentario A del artículo 9:509, relativo a la cláusula penal (Agreed payment for Nonperformance), entrega un caso de arras penales sin hacer distinción alguna: " $A$ agrees to sell his house to $B$, from whom he obtains a deposit for 20 per cent of the price to secure B's performance of the contract. $B$ refuses to complete the transaction. A may forfait the deposit" (Lando, 2000, p. 454). En realidad la confusión entre arras y cláusula penal solo se puede plantear respecto de las arras penitenciales o penales, no respecto de las confirmatorias. Vid. Gómez CALERO (1983) p. 72. 
allá del caso del Proyecto de Código Civil de García Goyena, de $1851^{19}$, hay pocos antecedentes legislativos de estas arras. Sin embargo, naturalmente la autonomía de la voluntad permite que se pacten ${ }^{20}$.

(4) Arras obligacionales: son aquellas que se entregan antes de la perfección del contrato. De esta forma, dotan de obligatoriedad, por vía indirecta, a los acuerdos preparatorios o precontractuales; razón por la que en lenguaje pandectístico corresponderían a las arras pacto imperfecto data ${ }^{21}$. Estas arras se observan con claridad en el Derecho de Chile 22 y Perú23. En el caso de las compraventas que se deben celebrar por escritura pública ${ }^{24}$, se hace evidente cómo las arras son el único elemento de coacción que conduce a las partes a la definitiva celebración del contrato ${ }^{25}$.

\footnotetext{
${ }^{19}$ Art. 1376: "Aunque hubiesen mediado arras o señal no podrá rescindirse el contrato por el hecho de allanarse el comprador a perderlas, o el vendedor a devolverlas duplicadas".

20 Cfr. Díez-Picazo (1983) p. 901; Albaladejo (1996) pp. 68 ss. Para este último autor, las arras penales solo alcanzan la virtud de la pérdida de las arras mas no la de restituirlas dobladas, de acuerdo a los argumentos históricos y dogmáticos que expone. La jurisprudencia española señala, por su parte, lo siguiente: "...el pacto arral (como cláusula accesoria de un contrato principal perfeccionado, generalmente una compraventa) puede desempeñar una de estas tres funciones (determinantes, respectivamente, de otras tantas clases de arras): como señal de la celebración de un contrato, en que la cantidad entregada es un anticipo o parte del precio (arras confirmatorias), como garantía del cumplimiento o arras penales, que se pierden si el contrato se incumple, pero que no permiten desligarse del mismo; y como arras penitenciales".. STS (1992).

21 “... las partes estipularon clara y expresamente que de no llevarse a cabo la compraventa prometida por causas imputables al promitente comprador o al promitente vendedor, el primero de ellos (en su caso) perdería las arras entregadas (un millón de pesetas) o el segundo (en el suyo) habría de devolverlas duplicadas (dos millones de pesetas), habiendo de entenderse incluida dentro de la expresión "causas imputables" la propia y exclusiva voluntad del contratante que se aparta del contrato (pues en ello radica la esencia institucional de las llamadas arras penitenciales o de arrepentimiento que regula el artículo 1454 del Código Civil y que las partes pactaron expresa e indubitadamente), siendo esto lo ocurrido en el presente supuesto litigioso, en el que el promitentevendedor se ha apartado voluntariamente del contrato litigioso (promesa bilateral de compraventa) y ha ofrecido devolver al promitente comprador las arras duplicadas (dos millones de pesetas)" STS (1996). Vid., sobre arras pacto imperfecto data, AFONSO (1995) pp. 60 ss.

22 C. C. chileno, art. 1803 en relación con artículos 1801, inciso 2º y 1554.

23 Cfr. C. C. peruano, art. 1480. Bajo el Título XIV, "Arras de Retractación”, no se establecen las arras penitenciales sino las obligacionales (al igual que bajo el Título XIII, "Arras Confirmatorias", no se habla de esta clase de arras sino de las que dogmáticamente se denominan penitenciales). Estas arras obligacionales acompañan un contrato preparatorio y permiten a las partes retractarse de la celebración del contrato definitivo. En caso de celebrase el contrato definitivo, quien recibió las arras debe restituirlas o imputarlas a su crédito según la naturaleza de la obligación (C. C. peruano, art. 1483).

${ }^{24}$ C. C. chileno, art. 1801 , inciso $2^{\circ}$, se refiere a la compraventa de bienes raíces, servidumbres, censos y de una sucesión hereditaria. Debe tenerse en cuenta que, en el Derecho chileno, la promesa de celebrar un contrato tampoco es consensual (C. C. chileno, art. 1554).

25 C. C. chileno, art. 1803: "Si se vende con arras, esto es, dando una cosa en prenda de la celebración... del contrato, se entiende que cada uno de los contratantes podrá retractarse; el que ha dado las arras, perdiéndolas; y el que las ha recibido, restituyéndolas dobladas". Esto es distinto respecto de las arras obligacionales del Derecho peruano, pues en este último país las arras obligacionales colaboran con el poder vinculante que ya emana del contrato preparatorio.
} 


\section{LAS FUENTES JURÍDICAS PRINCIPALES EN DERECHO JUSTINIANEO}

La información fundamental para el estudio de las arras en el Derecho justinianeo se encuentra en dos textos del Corpus Iuris: uno del Codex Iustiniani y otro de las Iustiniani Institutiones, respectivamente.

El primero corresponde a una constitución del año 528, C.I. 4, 21, 17:

Contractus venditionum vel permutationum vel donationum, quas intimari non est necessarium, dationis etiam arrharum vel alterius cuiuscunque causae, illos tamen, quos in scriptis fieri placuit, transactionum etiam, quas in instrumento recipi convenit, non aliter vires habere sancimus, nisi instrumenta in mundum recepta, subscriptionibusque partium confirmata, et, si per tabellionem conscribantur, etiam ab ipso completa, et postremo partibus absoluta sint, ut nulli liceat prius, quam haec ita processerint, vel a scheda conscripta, licet literas unius partis vel ambarum habeat, vel ab ipso mundo, quod necdum est impletum vel absolutum, aliquod ius sibi ex eodem contractu vel transactione vindicare; adeo ut nec illud in huiusmodi venditionibus liceat dicere, quod pretio statuto necessitas venditori imponatur vel contractum venditionis perficere, vel id, quod emtoris interest, ei persolvere.

1. Quae tam in postea conficiendis instrumentis, quam in his, quae iam scripta nondum autem absoluta sunt, locum habere praecipimus, nisi iam super his transactum sit vel iudicatum, quae retractari non possunt, exceptis emtionalibus tantum instrumentis, iam veli in scheda vel in mundo conscriptis, ad quae praesentem sanctionem non extendimus, sed prisca iura in his tenere concedimus.

2. Illud etiam adicientes, ut et in posterum, si quae arrhae superfacienda emtione cuiuscunque rei datae sunt sive in scriptis sive sine scriptis, licet non sit specialiter adiectum, quid super iisdem arrhis non procedente contractu fieri oporteat, tamen et qui vendere pollicitus est, venditionem recunsans, in duplum eas reddere cogatur, et qui emere pactus est, ab emtione recedens, datis a se arrhis cadat, repetitione earum deneganda ${ }^{26}$.

\footnotetext{
26 "Los contratos de venta, o permuta, o donación, que no es necesario que sean insinuados, al igual que de dación de las arras o de otra causa cualesquiera, pero que deban ponerse por escrito, tal como las transacciones en que se convino fueran consignadas en un instrumento, no tengan poder vinculante de otra forma que a menos que ya estén consignados en limpio en instrumentos y confirmados con la firma de las partes y también, si se han consignado por medio de notario, sin que estén por él mismo completados y, finalmente, estén confirmados por las partes, de manera que antes de haber procedido a todo esto no sea lícito por parte de nadie, por medio de papeles que sirvan como borradores, ya se trate de un borrador con la escritura de una o ambas partes, ya se trate de la misma copia en limpio que aún no esté concluida o aprobada, vindicar ningún derecho para sí desde aquel contrato o transacción; de manera que para tales ventas no es lícito decir que al vendedor se impone la necesidad de, por el precio establecido, perfeccionar el contrato de venta o cumplir con aquello que sea interés del comprador.

1. Prescribimos que esto tenga lugar respecto de la confección de instrumentos en lo sucesivo al igual que en aquellos que todavía no están confirmados, a menos que sobre ellos se haya transigido o juzgado, pues no podrá haber retracción respecto de estos, con excepción de los instrumentos de compra, ya estén contenidos en papeles que sirvan como borrador o en limpio, respecto de los cuales no extendemos la presente sanción, sino que concedemos que se sujeten a las antiguas regulaciones.
} 
Se trata de una disciplina nueva que viene en sustitución de los prisca iura (viejos derechos); vale decir, en sustitución de la costumbre oriental precedente. Como se observa con claridad, aquí se disciplina la forma de realizar la solemnidad de la scriptura (escritura) en varios negocios traslativos, incluidas las arras. De otro lado, también es claro que el contenido del pasaje presenta como hilo conductor, pese a la referida mención de otros negocios, la compraventa cum scriptura.

La información más relevante para los efectos de nuestra investigación es la siguiente:

i) para la conclusión de la compraventa escrita es necesario que el documento esté en limpio (in mundum receptum) y suscrito por las partes (subscriptionibusque partium confirmata); y, si lo redactó un notario, que el documento en limpio esté suscrito por el propio notario (completum), y consignado por las partes (et postremo partibus absolutum);

ii) si se ha acordado celebrar la venta por escrito, ni aun la entrega de la cosa o el pago del precio pueden perfeccionar el contrato, sino solo la escritura hecha conforme a lo que se establece en la propia constitución; por lo que tampoco los borradores o documentos preliminares, aunque estén firmados por una e, incluso, por ambas partes, tienen poder vinculante (ut nulli liceat prius, quam haec ita processerint... quod necdum est impletum vel absolutum, aliquod ius sibi ex eodem contractu vel transactione vindicare).

iii) si se dieron arras, por escrito o sin escritura, durante el lapso en que todavía no se ha concluido el cumplimiento de las formalidades de la compraventa (si quae arrhae superfacienda emtione... datae sunt sive in scriptis sive sine scriptis); $\mathrm{y}$, a su vez, se produce el arrepentimiento de alguna de las partes (qui vendere pollicitus est, venditionem recunsans... qui emere pactus est, ab emtione recedens): el que rehúsa vender deberá devolverlas dobladas y el que rehúsa comprar perderá las arras; todo esto, por efecto de la propia constitución, vale dercir, aunque nada se haya dicho del destino que estas debían seguir (licet non sit specialiter adiectum, quid super iisdem arrhis non procedente contractu fieri oporteat).

En resumen:

a) aparece claramente en el contexto que las arras obligacionales, dadas por escrito o sin escritura, acceden a un acuerdo no vinculante (si quae arrhae superfacienda emtione... datae sunt sive in scriptis sive sine scriptis); $y$

b) no hay locus penitentiae si la escritura ha sido convenientemente completada; pues una vez que ello ha acaecido, la venta queda perfecta.

2. Agregando todavía esto, para que en lo sucesivo, si son dadas arras en la realización de una compra de cualquier cosa, o por escrito o sin escritura, aunque no se haya dispuesto especialmente lo que deba hacerse con dichas arras si no se sigue el contrato, no obstante se obligue a quien ofreció vender, al rehusar la venta, a restituirlas duplicadas, y a quien acordó comprar, al arrepentirse de la compra, a perder las arras dadas por él, denegándosele la repetición de estas". 
Ahora apreciemos lo que dicen las I. Inst. 3, 23, pr., respecto de las arras:

Emptio et venditio contrahitur, simulatque de pretio convenerit, quamvis nondum pretium numeratum sit, ac ne arra quidem data fuerit; nam quod arrae nomine datur, argumentum est emptionis et venditionis contractae. Sed haec quidem de emptionibus et venditionibus, quae sine scriptura consistunt, obtinere oportet; nam nibil a nobis in huiusmodi venditionibus innovatus est. In his autem, quae scriptura conficiuntur, non aliter perfectam esse venditionem et emptionem constituimus, nisi et instrumenta emptionis fuerint conscripta, vel manu propria contrahentium, vel ab alio quidem scripta, a contrahentibus autem subscripta, et, si per tabelliones fiunt, nisi et completiones acceperint, et fuerint partibus absoluta. Donec enim aliquid ex his deest, et poenitentiae locus est, et potest emptor vel venditor sine poena recedere ab emptione. Ita tamen impune iis recedere concedimus, nisi iam arrarum nomine aliquid fuerit datum; hoc etenim subsecuto, sive in scriptis sive sine scriptis venditio celebrata est, is, qui recusat adimplere contractum, si quidem est emptor, perdit quod dedit, si vero venditor, duplum restituere compellitur: licet super arris nihil expressum est $t^{27}$.

Hay dos partes claramente diferenciadas en este texto.

De la primera parte, los contenidos que nos interesan son los siguientes:

i) se refiere a las ventas sine scriptura, respecto de las cuales repite el principio romano clásico: la venta se perfecciona por el solo consentimiento ${ }^{28}$;

ii) si se dan arras, estas solo constituyen un argumento, o prueba, de que se ha celebrado la compraventa (argumentum est emptionis et venditionis contractae).

iii) se declara expresamente que se ha mantenido la tradición clásica ("nada se ha innovado", nibil... innovatus est) que, a este respecto, podemos encontrar en las Gai Institutiones 3, 139.

De la segunda parte tendremos que concentrarnos en la información siguiente:

i) se refiere a la compraventa escrita, la cual no se perfecciona sino hasta que se cumplan los requisitos pertinentes (quae scriptura conficiuntur, non aliter perfec-

\footnotetext{
27 "La compraventa se contrae a través del acuerdo del precio, aunque todavía se haya pagado el precio y a pesar de que no hayan sido dadas arras; pues lo que se da bajo la designación de arras es un argumento de que se ha celebrado la compraventa. Pero esto se debe aplicar para las compraventas que se celebran sin escritura; pues nada se ha innovado respecto de estas compraventas. En las otras, que se celebran por escrito, hemos decidido por medio de una constitución que no están perfectas las compraventas sin que estuvieran consignadas en instrumentos de compra, ya sea que hayan sido escritos por propia mano, o por medio de otro para que fueran suscritos por las partes, y si fueran confeccionados por notarios, sin que fueran concluidos y confirmados por las partes. En efecto, mientras algo de esto no esté hay lugar al arrepentimiento y puede el comprador o el vendedor apartarse impunemente de la compra. Sin embargo, asi les concedimos apartarse impunemente, a menos que algo haya sido dado a título de arras; si de esta forma ha ocurrido, ya por escrito ya sin escritura está celebrada la venta, aquel que rehúsa cumplir el contrato, si es el comprador, pierde lo que dio, si es en cambio el vendedor, es compelido a restituir el doble: aunque no se haya dispuesto nada respecto de las arras".

28 GALLO (1964) pp. 33 ss.
} 
tam esse venditionem et emptionem constituimus, nisi et instrumenta emptionis fuerint conscripta...).

ii) como en este caso el simple acuerdo no es vinculante ${ }^{29}$, consecuentemente, las partes pueden retractarse antes de que se completen las formalidades (Donec enim aliquid ex his deest, et poenitentiae locus est, et potest emptor vel venditor sine poena recedere ab emptione).

i) pero si han mediado arras, si bien puede haber arrepentimiento, por las razones antes apuntadas, este no es impune sino que queda sujeto a la sanción arral (Ita tamen impune iis recedere concedimus, nisi iam arrarum nomine aliquid fuerit datum).

ii) cuando hayan sido dadas arras (hoc etenim subsecuto [arrarum nomine... fuerit datum]), tanto respecto de las ventas ya celebradas, tanto cum scriptura como sine scriptura (sive in scriptis sive sine scriptis venditio celebrata est), su sanción propia opera (qui recusat adimplere contractum... perdit quod dedit... duplum restituere compellitur) a la manera de una cláusula legal (licet super arris nibil expressum est).

En resumen:

a) existe un régimen clásico de compraventa consensual y un régimen justinianeo de compraventa escrita. En este último, el solo consentimiento no es vinculante.

b) se dice que para la compraventa consensual, las arras solo son confirmatorias.

c) se dice que para la compraventa escrita, las arras son obligacionales, de manera que operan durante el tiempo en que todavía no se han concluido las formalidades en la compraventa escrita.

d) a manera de desarrollo de lo anterior (y aquí la sección más complicada del texto, sobre la que se concentrará nuestra exposición), vale decir, respecto de los efectos de la dación de arras (hoc etenim subsecuto), se dice que su sanción va a operar aun cuando la compraventa ya esté completamente celebrada, tanto si es escrita como si es consensual (sive in scriptis sive sine scriptis venditio celebrata est). Por lo tanto, se establecen arras penitenciales.

Hasta aquí la consideración escueta de lo que las fuentes dicen; mas ahora queda por ver el problema de la armonización de estos textos, para desentrañar su verdadero significado y alcance ${ }^{30}$.

\footnotetext{
${ }^{29}$ GALlo (1964) pp. 12 ss.

30 Marasinghe (1973) pp. 349 ss. No cree que exista problema alguno de armonización, lo que aún no terminamos de comprender.

${ }^{31}$ FrezZA (1962) p. 305.
} 


\section{EL PROBLEMA EXEGÉTICO DE LAS FUENTES}

Como ha observado Frezza ${ }^{31}$, hay dos órdenes de problemas exegéticos: uno, que podríamos llamar de "concordancia interna", que se refiere a la armonía total que ha de presentar el contexto de cada uno de ambos fragmentos; y, otro, de "concordancia externa”, que consiste en relacionar el Codex Iustiniani con las Iustiniani Institutiones según un significado que no engendre contradicciones entre ellos.

\section{III.A. PROBlemas DE CONCORDANCIA INTERNA}

En cuanto a la concordancia interna de Código, en general los autores no han encontrado mayores problemas de armonía entre los diversos párrafos de esta constitución. Mas nosotros nos permitimos señalar dos: primero, que mientras la primera parte de pr. hace referencia a una larga lista de negocios traslativos de dominio (compraventa, permuta, donación, transacción y hasta la propia datio arrharum), el resto de la ley toma en cuenta exclusivamente la compraventa, y las arras en cuanto se relacionan con la venta; segundo, la redacción que se da al pasaje en la parte donde enumera los diversos tipos de negocios, es verdaderamente atormentada, como ya había observado ArangioRuiz ${ }^{32}$.

Cuando de Código pasamos a revisar la coherencia interna de las Iustiniani Institutiones, los problemas se hacen más agudos. Sobre todo al comparar la primera parte que trata de la venta consensual, con la segunda que recoge o aparentemente procura recoger las reformas de la constitución del año 528, sobre la compraventa escrita ${ }^{33}$.

La primera parte declara explícitamente que quiere conservar el régimen clásico de la perfección del contrato por el consentimiento simple en la venta sine scriptis, de manera que las arras tengan valor confirmatorio; pero en la segunda parte se dice que las arras serán penitenciales tanto en la venta consensual como en la escrita.

Desde el punto de vista textual, el núcleo del problema se presenta con la parte que señala "venditio celebrata est". Pues es desde ahí que el fragmento dé un alcance general a la poenitentia (arrepentimiento) que alcanza tanto a la compraventa "in scriptis" como a la "sine in scriptis".

Si se señala: "sive in scriptis sive sine scriptis venditio celebrata est", ciertamente la literalidad del fragmento alude, tanto respecto del negocio consensual como del formal, a una compraventa ya perfeccionada (venditio celebrata est). Cualquiera sea el significado que en definitiva se atribuya a todo el contexto del pasaje, la redacción en este punto es de una desafortunada oscuridad.

Si las arras intervienen cuando la venditio celebrata est, y se trata de una venta sine scriptis, es decir, consensual, evidentemente esta ha precedido a las arras. Por lo tanto, puede emplearse con propiedad el pretérito perfecto "celebrata est".

Pero si la venta es cum scriptura, entonces su celebración será posterior a la datio arrharum según la información que tenemos del Codex Iustiniani y, asimismo, según la

32 ARANGIO-Ruiz (1956) p. 98.

33 GALlo (1964) p. 29. 
propia Instituta en las líneas inmediatamente precedentes. De hecho, anteriormente el texto se refería expresamente al arrepentimiento producido precisamente antes de la conclusión de las formalidades de la escritura. Ahí se dice: aliquid ex his deest, et poenitentiae locus est, et potest emptor vel venditor sine poena recedere ab emtione. Lo natural sería que se siguiera hablando de la compraventa in scriptis, sobre todo en vista de la conexión que parece ofrecer la expresión "hoc etenim subsecuto"; pero lo cierto es que a continuación no se dice "superfacienda emtione", como en el Codex Iustiniani, ni se utiliza otra expresión similar, sino que se dice "venditio celebrata est". Por ello, la forma verbal "celebrata est", referida a la dación de arras en relación con la compraventa escrita, da la impresión de estar en un tiempo inadecuado.

En todo caso, la Paráfrasis griega de Teófilo nos entrega lo que podríamos considerar una interpretación auténtica del pasaje; y ahí se dice: "Sive in scriptis sive sine

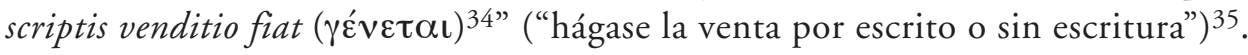

Tanto a partir de esta redacción como del principio conservador (no distorsionador) de lo que las fuentes dicen en el trabajo romanístico, en realidad parece que no se puede desvirtuar el tiempo verbal utilizado en las Iustiniani Institutiones; y si tratamos de conservar el sentido más literal de "celebrata est", entonces habría que concluir que, a través de un latín imperfecto no insólito en los compiladores, se viene a decir que la sanción arral opera tanto respecto de la venta "consensual" como de la venta "escrita".

Bajo esta perspectiva, la inclusión de la poenitentia constituye una doble innovación.

Como ahora puede operar la sanción arral respecto de una compraventa consensual que "celebrata est", es evidente que las arras han excedido su función confirmatoria clásica dando lugar a la poenitentia; lo que sorprende si se considera que la primera parte de las Iustiniani Institutiones ha copiado las Gai Institutiones 3, 139, añadiendo incluso que nada se había innovado (nibil... innovatus est).

Respecto de la compraventa escrita, también se excede abruptamente el carácter obligacional atribuido por la constitución de 528, donde no se alude a una compraventa perfeccionada (celebrata est), sino a una compraventa futura (superfacienda emptione). Esto también sorprende, pues, como decíamos, ahora también habrá lugar a la poenitentia respecto de compraventas escritas perfectas.

En este último caso, por tanto, obviamente la referencia se realiza respecto del momento posterior al perfeccionamiento de las solemnidades, o sea, cuando celebrata est", o también, cuando la "venditio (in scriptis) fiat", como dice la paráfrasis.

En cuanto a las arras en la compraventa escrita, entendemos que, además de lo señalado, tras el incómodo "celebrata est" subyace la inclusión del régimen de la dación arral previa al perfeccionamiento del contrato, pues de otra manera queda trunco en el texto el tratamiento del consentimiento in itinere, del que solo se determina la situación correspondiente a la falta de arras y, luego, cuando se anuncia lo que ocurrirá si en aquel momento intervienen, se da paso al enunciado general "sive in scriptis sive sine scriptis".

${ }^{34}$ Cfr. Paraphrasis Theophili (ed. Ferrini p. 351 ss.). Vid. CarUsi, (1930) p. 554.

35 Cfr. Arangio-Ruiz (1956) p. 103. 
Resulta bastante evidente que también se quiere, con esta fórmula imperfecta, abarcar tal situación (hoc etenim subsecuto), donde no podrían las arras cumplir con otra función que la obligacional griega.

En conclusión, se trataría de una regulación general que abarca todas las compraventas y las correspondientes funciones de las arras (obligacionales, en la escrita y penitenciales en ambas clases de compraventa).

En verdad, entonces, la redacción debe llevar a la conclusión de que se trata de una tercera sección en el texto. Justiniano le ha dado a las arras, en ambas compraventas, la función llamada penitencial, es decir, de arrepentimiento, que en Derecho clásico se lograba en la compraventa consensual, gracias a la cláusula comisoria y no a las arras, pese a haber declarado, en la primera parte del texto, que en la venta consensual las arras son confirmatorias y que "nihil... innovatum est".

Se advierte, pues, que cada uno de los textos, aisladamente, no con poca dificultad, salva su coherencia interna, pero cuando procuramos combinar el contenido de ambos, la dificultad se hace insuperable por la vía sistemática.

\section{III.B. PROBLEMAS DE CONCORDANCIA EXTERNA}

El nudo del problema está en la frase "sive in scriptis sive sine scriptis", que se contiene en ambas fuentes.

Ahora bien, mientras en el Codex Iustiniani la frase se refiere a las arras, en las Iustiniani Institutiones se relaciona con la venta, o dicho en otras palabras, Código no hace cuestión de si la compraventa es o no escrita (pues todo el texto se refiere únicamente a la compraventa escrita), sino si las arras se dan o no por escrito. De esta forma, se vendría a decir lo siguiente: "sea que las arras se den por escrito, sea que se den sin escritura, establecerán una pena para el caso de arrepentimiento producido antes de que se perfeccione la compraventa escrita"; La Instituta de Justiniano, por el contrario, parece decir: "sea que la venta se haya celebrado por escrito, sea que sin escritura, las arras establecerán una pena".

Como ya hemos advertido, el texto de Instituta no es autónomo, sino que procede de la conjunción de dos fuentes anteriores, que son Gai Institutiones 3, 139 y el propio texto paralelo de Codex Iustiniani ${ }^{36}$.

Por ello, no se puede negar que son muy atendibles los motivos para creer que la frase en cuestión, "sive in scriptis, sive sine scriptis", debiera tener el mismo significado tanto en el Codex Iustiniani como en las Iustiniani Institutiones. Y por esta razón, cobra importancia las fechas de promulgación de cada texto: mientras la constitución del Codex Iustiniani es del año 528, y fue promulgada junto a la primera versión del Codex el año 529, las Iustiniani Institutiones fueron promulgadas el año 533; ahora bien, tampoco se puede olvidar el segundo momento editorial que implica, respecto de la constitución mencionada, la nueva promulgación del Codex Iustiniani el año $534^{37}$.

\footnotetext{
36 GALLO (1964) pp. 27 ss.

37 Vid., por todos, Cannata (1996) pp. 121 ss.
} 
Así, un grupo de especialistas sostiene que el texto del Codex Iustiniani, correspondiente al año 528, debe dar sentido a las Iustiniani Institutiones, del año 533, sobre todo considerando su mayor grado de especialidad en el tratamiento de la compraventa escrita y, asimismo, que su edición final, el año 534, se hizo teniendo a la vista el texto de Instituta; por ello, de haberse introducido algún cambio en esta relativo a la compraventa escrita, esto tendría que haberse reflejado en la versión final del Codex Iustiniani.

Por ejemplo, para Arangio-Ruiz ${ }^{38}$, tanto por la anterioridad como por la especialidad, se debe preferir Código por sobre Instituta; siendo esta una simplificación con fines didácticos que viene a enturbiar lo que señala la primera fuente, resulta que en realidad solo existirían las arras obligacionales de la compraventa escrita y las confirmatorias de la no escrita, y el agregado justinianeo de la llamada función penitencial solo habría operado respecto de esta última, es decir, de la compraventa consensual. Así, Arangio-Ruiz ${ }^{39}$ observa que hubiese sido mejor la redacción "sive in scriptis celebranda sive sin scriptis celebrata venditio sit"; con ello, quiere atribuir al texto el sentido de que, mientras en materia de compraventa escrita las arras ya habían sido referidas al momento anterior a la perfección del contrato, las arras a las que ahora se refieren las Iustiniani Institutiones son las que suceden la compraventa consensual, única de la que se puede decir que celebrata est ${ }^{40}$.

Partiendo desde premisas similares, para algunos autores "sive in scriptis sive sine scriptis" habría de referirse a las arras, como aparece en el Codex Iustiniani, y no a la compraventa como aparece en las Iustiniani Institutiones.

Tal es el caso de Zulueta ${ }^{41}$, Marasinghe ${ }^{42}$, Lisowski ${ }^{43}$, Talamanca ${ }^{44}$, Zimmer$\operatorname{mann}^{45}$ y Thomas ${ }^{46}$, quienes no creen en la introducción de las llamadas arras penitenciales en ningún caso: ni en la compraventa escrita, que en el modélico pasaje de Código se refiere a la compraventa in scriptis imperfecta, ni tampoco, a diferencia de ArangioRuiz, en la compraventa consensual, respecto de la cual no cabe el arrepentimiento según el Derecho clásico, por lo que las arras son meramente confirmatorias, y no cabe otra función desde que se ha dicho que "nihil... innovatus est".

Para Zulueta ${ }^{47}$ y Marasinghe ${ }^{48}$, por tanto, lo que se podía dar por escrito o sin escritura en las Iustiniani Institutiones son las propias arras que anteceden a la conclusión de la compraventa escrita. De hecho, si en Instituta se hubiese querido decir algo más que esto -es decir, se hubiese querido introducir las arras penitenciales-, ello se

\footnotetext{
38 (1956) p. 103.

39 (1956) p. 103.

${ }^{40}$ Penitenciales en opinión de Arangio-Ruiz (1956) p. 101.

41 Zulueta (1945) p. 24.

42 Marasinghe (1973) p. 352.

43 LISOWSKI, (1950) pp. 74 ss.

44 TALAMANCA (1953) pp. 84 ss.; TALAMANCA (1963) pp. 226 ss.

45 ZiMMERMANN (1992) pp. 233 y 234.

46 Thomas (1956) pp. 277 ss.

47 Zulueta (1945) p. 24.

48 Marasinghe (1973) p. 352.
} 
habría reflejado en la edición final de Código, del año $534^{49}$, y ciertamente esto no ocurre. Por cierto, el problema de la construcción "celebrata est" no queda resuelto en caso alguno.

Según Lisowski ${ }^{50}$, el Codex Iustiniani se habría abocado a configurar el régimen de la compraventa escrita en la cual, mientras no se cumplan todas las formalidades, las partes pueden desistirse impunemente del contrato; mas cesa tal impunidad con la intervención de las arras (contractus dationis arrarum), las que pueden ser tanto escritas como no escritas ${ }^{51}$, como lo demuestran varios papiros ${ }^{52}$. A su vez Instituta se refiere en su primera parte a la compraventa, limitándose a reproducir el pasaje del argumentum gaiano, luego hace una tajante división inmediatamente antes de pasar a la compraventa escrita (nibil... innovatus est), dando por concluido el tema, de manera que todo lo posterior sería un resumen de lo expuesto en Código, por lo que la frase "sive in scriptis sive sine scriptis" se referiría a las arras obligacionales de la compraventa escrita ${ }^{53}$. Ahora para superar el escollo que representa el "venditio celebrata est" de Instituta, Lisowski sugiere que el ablativo "Hoc etenim subsecuto" claramente se articula con la frase de las arras que le precede, de ahí que la lectura tendría que ser "etenim si arrarum nomine aliquid fuerit datum sive in scriptis sive sine scriptis" 54 .

En suma, Lisowski ${ }^{55}$ ha creído que una pequeña corrección textual en Instituta, aclara todo convenientemente, ya que con un cambio de coma, la frase problemática puede quedar también referida a las arras, de manera que se pueda leer: "Les concedemos, asi, apartarse impunemente (del cumplimiento de una compraventa escrita todavía imperfecta) a no ser que ya se hubiera dado algo en calidad de arras, pues si eso se hubiera hecho sea por escrito, sea sin escritura, la venta ha sido celebrada". En Instituta el texto aparece de esta forma: "hoc etenim subsecuto, sive in scriptis sive sine scriptis venditio celebrata est". Lisowsky propone la siguiente redacción para Instituta: "hoc etim subsecuto sive in scriptis sive sine scriptis, venditio celebrata est" 56 .

Mas esta explicación no satisface, pues si bien se equipara la mención a las arras escritas en ambos textos, en Código la alusión a las arras se enmarca en la inconclusión de las formalidades literales de la compraventa, de manera tal que el problema que representa en Instituta la frase "venditio celebrata est", respecto de la compraventa escrita, persiste, tal como lo hace notar Thomas ${ }^{57}$, sobre todo considerando el problema que para esta construcción presenta el "superfacienda emptione" de Código ${ }^{58}$.

\footnotetext{
49 MARASinghe (1973) p. 352.

50 LISOWSKI (1950) pp. 74 ss.

${ }^{51}$ LISOWSKI (1950) p. 74.

52 Arras escritas: Lond. 2 p. 211, BGU. 446, BGU. 240; arras no escritas: CPR. 19, Lond. 2 pp. 204-205.

53 LISOWSKI (1950) p. 75.

${ }^{54}$ LISOWSKI (1950) p. 76.

55 LISOWSKI (1950) pp. 75 ss.

56 Vid. ThOMAS (1956) p. 264.

57 Thomas (1956) pp. 268 y 269.

58 NARDI (1968) p. 221.
} 
Talamanca ${ }^{59}$, al igual que Zimmermann ${ }^{60}$, supone que en las Iustiniani Institutiones "venditio celebrata est" no corresponde propiamente a un error de redacción por el que se expresó incorrectamente el contenido del Codex Iustiniani. En este caso "venditio" no equivaldría a "compraventa" sino que equivale directamente a "contrato arral", datio arrarum, la que puede ser verbal o escrita según la constitución de $528^{61}$. En las Iustiniani Instituiones se habría dicho "venditio" escrita o no escrita, solo por reflejo de la praxis griega, en virtud de cuyas estructuras el contrato consensual romano aparecía como semejante al contrato arral, que de alguna manera servía como contrato preparatorio de la subsiguiente compraventa real.

Ahora bien, según Talamanca ${ }^{62}$, tal como Instituta está redactada, resulta inadmisible, que se pueda hablar de arras que se refieren a una venta escrita ya celebrada (celebrata est $)^{63}$, pues se excluiría la disposición modélica de Código respecto de la compraventa futura, donde las arras se dan antes de la conclusión de las formalidades de la escritura. Esto, por lo demás, también aparece en la propia Instituta en las líneas que preceden al problemático fragmento "sive in scriptis sive sine scriptis venditio celebrata est". De otro lado, tampoco considera sostenible que en esta parte Instituta se refiera a una compraventa in scriptis tan solo proyectada ${ }^{64}$, como lo propuso en su día ArangioRuiz $^{65}$, pues con toda claridad esta interpretación tampoco se condice con el "celebrata est".

Verdaderamente, a primera vista, las razones de Talamanca parecen buenas: se debe preferir el texto de Código, más específico en cuanto a su intención (no se trata otra cosa más que la compraventa cum scriptura) ${ }^{66}$, que el de Instituta, donde se trata el tema de la compraventa y de las arras desde un punto de vista escolar, como en un libro de texto; además, Código se refería a la compraventa "griega" (cum scriptura). Así, la parte de esta fuente, "... sive in scriptis sive sine scriptis"..., estaría relacionada con la datio arrarum unida a una compraventa futura (superfacienda emptione ${ }^{67}$, conservando las arras, en consecuencia, la función obligacional que desempeñaba en Oriente. Dicho contrato arral habría estado reconocido y tipificado por Justiniano (lo que diferenciaría a este de la pura compraventa griega), merced al mismo pasaje de Código ${ }^{68}$, donde no ve más interpolación, en cuanto al repertorio de negocios enumerados que el de la transacción ${ }^{69}$. Ahora bien, como el contenido de Instituta debe explicarse por el contrato arral a que se refería Código, los compiladores enfrentados al negocio arral helenístico, desde

\footnotetext{
59 TALAMANCA (1953) pp. 84 ss.

60 ZiMMERMANN (1992) pp. 233 y 234.

61 TALAMANCA (1963) p. 334.

62 TALAMANCA (1953) pp. 84 ss.

63 TAlamanca (1963) p. 333.

64 TAlamanca (1963) p. 332.

65 (1956) p. 103.

66 Talamanca (1963) p. 330.

67 Talamanca (1963) p. 326.

68 TALAMANCA (1963) p. 329.

69 Talamanca (1963) p. 327 n. 14.
} 
un punto de vista romano, lo traducen, justamente, a la compraventa obligacional romana ${ }^{70}$, de manera tal que no debe extrañar la confusión. De esta forma, el "sive in scriptis sive sine scriptis" de Instituta debe entenderse en el sentido que la compraventa futura a que alude Código (superfacienda emptione), está acordada como simple negocio (celebrata est), ya sin todas las formalidades literales concluidas, ya de manera puramente verbal ${ }^{71}$. Esta explicación deja incólume todo cuanto se refiere a la compraventa sine scriptis, pues la reforma justinianea no la tocaría ${ }^{72}$.

Esta interpretación, sin embargo, presenta graves dificultades que la hacen inadmisible. Ante todo, rompe la coherencia interna de Instituta, ya que en la primera parte llamaría "venditio" a la compraventa consensual y en la segunda parte, a las arras obligacionales $^{73}$; además, parece extraño que en un texto donde se distribuyen todos los efectos de la compraventa según si esta es o no escrita, introduzca el redactor una alusión absolutamente impertinente sobre arras escritas o no escritas.

De dicha introducción de las arras escritas o no escritas como una negociación, denominada venditio, que "celebrata est", habría que deducir que mientras Código no atribuye perfección a la compraventa cum scriptura mientras no se cumplan todas las formalidades, en su tratamiento general Instituta considera celebrada (celebrata est), en pie de igualdad, pese a sus diversos modos y momentos de conclusión, tanto las compraventas in scriptis, como las sine scriptis y también las in scriptis imperfectas en que han mediado arras. Hasta aquí es claro que la conjetura va demasiado lejos. En efecto, si partiéramos de la base, como hace esta teoría, de que en Instituta se han identificado el contrato arral con la compraventa obligatoria, en circunstancias que aquel puede celebrarse, si estamos a lo que nos revela Código, por escrito o sin escritura, tendríamos que: a) si las partes dieran arras antes de la celebración de una compraventa escrita, habría desde ya compraventa sine scriptum; y b) si, al contrario, las dieran escrituradas, habría desde ya compraventa in scriptis. De acuerdo a la visión que los compiladores habrían dado al contrato arral, según Talamanca, el ulterior desarrollo que hemos presentado no puede ser distinto, pues las arras obligacionales funcionarían en la medida que se haya determinado la cosa y el precio. Pero si esto fuera así, no quedaría lugar, en consecuencia, a la dilación de los efectos vinculantes que tanto Código como Instituta prevén expresamente para el caso de la compraventa escrita. Así, la teoría de Talamanca termina por naufragar en un sinsentido.

Es atinada la observación de Gallo $^{74}$ en cuanto a que esta tesis arrojaría, además de las compraventas sine scriptis e in scriptis, una tercera que sería la "sive in scriptis sive sine scriptis"... arral, de Instituta; pero, sobre todo, nos parece válida la observación de Schuster ${ }^{75}$, de que las arras, inclusive en el Derecho bizantino, son un negocio real, por

\footnotetext{
70 Talamanca (1963) p. 326.

71 Talamanca (1963) p. 332.

72 Talamanca (1963) cit. p. 330.

73 FreZZA (1962) p. 307.

74 Gallo (1964) p. 251.

75 SCHUSTER (1959) pp. 53 ss.
} 
lo que la obligación nace no en virtud de una convención o de una escritura, sino solo por la consignación de la cosa dada en arras: inclusive el contraargumento de Talamanca, que apoya la existencia de arras "escritas" en la primera parte de pr., carece de consistencia, como veremos luego.

Thomas ${ }^{76}$ sugiere la posibilidad de manipulaciones en Instituta, donde el compilador habría unido la praxis griega respecto de las compraventas (traslativas) no escritas, al tratamiento jurídico de las arras, en circunstancias que, en este último caso, estas son meramente evidenciarias respecto de la compraventa consensual.

La hipótesis sobre la que trabaja este romanista ${ }^{77}$, que de alguna forma ya hemos expuesto, se funda en que el desarrollo del sistema romano de consensualidad es único entre los sistemas de la Antigüedad, especialmente el griego, donde la compraventa era una transacción al contado (cash transaction), como lo muestran los documentos del sistema helenístico de épocas ya tardías ${ }^{78}$. Tratándose de cosas importantes, la transferencia del dominio se hacía a través de escritos de carácter publicitario y, en caso contrario, simplemente contra el pago del precio.

Mientras en la compraventa romana las arras eran solo evidenciarias e, incluso, no pierden este carácter primordial cuando se les agregaba función penal por el pacto de las partes (lex commissoria), en Oriente, ante la falta de fuerza vinculante del consenso, los contratantes podían apartarse impunemente del acuerdo, quedando solo indirectamente vinculados por la correspondiente dación arral (función desconocida en Roma) ${ }^{79}$, que podía representar gran parte del precio, por ejemplo, un $66 \%{ }^{80}$. Este paralelismo se mantiene incluso luego de la concesión general de ciudadanía otorgada por Caracalla el año 212, como lo demuestran los papiros y el Libro Siro-Romano, de manera que para el incumplidor no existió más sanción que la pena arral ${ }^{81}$.

En época postclásica y prejustinianea la práctica oriental, que habría comenzado a desarrollarse, según Thomas ${ }^{82}$, en época clásica con Escévola, ya a partir del siglo II ${ }^{83}$, consistía justamente en agregar a las arras un pacto comisorio. De esta forma, se superaba el problema que les representaba a los habitantes de Oriente el carácter meramente confirmatorio de las arras romanas, agregando a la compraventa lo que ellos consideraban una vía alternativa de resolución, más afín con su cultura jurídica. A pesar de estar de acuerdo con este romanista, no compartimos sus razones, pues de los textos romanos

\footnotetext{
76 ThOMAs (1956) pp. 277 ss.

77 Thomas (1956) p. 254.

78 Thomas (1956) pp. 261 y 262.

79 Thomas (1956) pp. 254 y 255.

80 Pap. Lond. 334.

81 ThOmas (1956) pp. 257.

82 Thomas (1956) pp. 258

83 Cfr. D. 18, 3, 6, 2; 18, 3, 8; C. I. 4, 54, 1. Parece cierto que en esta época los juristas empiezan por vez primera a preocuparse del Derecho de las provincias. Seguramente este interés no se debió a un interés científico, sino que fue consecuencia de las políticas de concentración del poder delineadas desde el gobierno de Adriano, del cual los juristas pasan a ser funcionarios. Por lógica consecuencia, dichas políticas desembocan en la idea recurrente de conducir la unidad política a través de la unidad jurídica. Vid. D’ORS (1997) p. 85.
} 
en que se basa resulta prematuro derivar tal conclusión: no son los orientales quienes aprecian en la lex commissoria una vía de resolución que acercaba su estructura arral griega al sistema contractual romano, sino que son los juristas occidentales quienes dan tal lectura a los casos llegados a la Cancillería imperial para adaptarlos al molde jurídico de la urbs, como ya lo sugiere también Archi ${ }^{84}$. Más razonable es deducir de las propias reformas justinianeas al régimen de las arras tal consecuencia, como lo expone D'Ors ${ }^{85}$.

Según Thomas, la frase final de Código "sive in scriptis sive sine scriptis" se refiere a la compraventa griega y no a las arras romanas (quae arrae datae sunt) ${ }^{86}$, puesto que así conecta de manera más coherente con el resto del texto, que se refiere al tratamiento de la compraventa escrita incompleta: "superfacienda emptione... qui vendere pollicitus est... qui emere pactus est... non procedende contractu" 87 . Justiniano, entonces, habría aplicado la noción helenística de las arras y de la compraventa no vinculante, en este caso por no reunir todos sus requisitos. Pero además de esta razón exegética para referir la parte final del texto a la compraventa, Thomas ${ }^{88}$ aporta otra dogmática para no referirla a las arras. Aunque los papiros y el propio comienzo de Código den cuenta de que las arras se puedan celebrar con o sin escritura, naturalmente en un sistema que desconoce el vínculo consensual las arras no pueden sino ser un negocio real y, por lo demás, aunque se las escriture estas siguen siendo un negocio real (por si se creyera que pueden tener eficacia literal), pues la pena arral solo puede funcionar cuando efectivamente han sido dadas.

Así entonces, el contenido de Código habría sido vertido en Instituta, la que, teniendo fuerza de ley y en su carácter de libro didáctico elemental, articula aquella disposición con el tratamiento general de la compraventa, agregando en materia de arras en la compraventa consensual una función propia de la práctica helenística, habida cuenta de que "práctica" es algo diverso de "Derecho aplicable", por ello no se coordinan bien con los principios de Código y Digesto ${ }^{89}$. Por lo tanto, concluye que en Instituta "celebrata est" no se debe referir a compraventa escrita perfecta, sino que a la compraventa escrita en formación, que es lo señalado por Código y, asimismo, las arras no deben entenderse como penitenciales en la compraventa no escrita, donde solo son confirmatorias, tal como lo señala al inicio la propia Instituta, pues la distorsión del compilador consiste justamente en haber insertado aquí la práctica griega donde las arras operan penando el desistimiento desde que hay acuerdo, aunque sea puramente verbal, sobre cosa y precio $^{90}$. Esta reforma, tendente a extender la posibilidad de poenitentia a la compraventa no escrita quedaría probada fuera del Corpus Iuris por la Paráfrasis de Teófilo, la que refiere la frase de Instituta a las arras cum scriptu$r a^{91}$. Esto último sería la prueba de la manipulación, pues no se puede dejar de tomar

\footnotetext{
${ }^{84}$ ARCHI (1981) p. 695.

85 D'Ors (1958) pp. 80 y 81

86 ThOMAs (1956) p. 266.

87 THOMAS (1956) p. 265.

88 ThOMAS (1956) pp. 257 y 267.

89 Thomas (1956) pp. 264 y 265.

90 Thomas (1956) pp. 269 y 270.

91 Thomas (1956) p. 264.
} 
en serio la declaración de Instituta, que resulta incoherente al contrastarla con el colofón, en cuanto a que no se había innovado respecto de las compraventas no escritas (nibil... innovatus est) ${ }^{92}$.

Respecto de esta teoría ha tenido tan ilustre contradictor como don Álvaro $\mathrm{D}^{\prime} \mathrm{Ors}{ }^{93}$, quien rebate el pretendido manejo compilatorio sobre la base de los tres argumentos que aquí presentamos: primo, no se deben suponer interpolaciones en pasajes de Instituta que, como este, no proceden de otra fuente anterior sino que son justinianeas de primera mano; secundo, porque no se descubre la razón que pudo inducir a corromper el texto; tertio, porque parece muy probable que la frase "sive in scriptis sive sine scriptis" debe tener el mismo sentido en ambos pasajes, y, si los compiladores tomaron la frase del Código para introducirla en la Instituciones, y en el Código se refiere al modo de constituir las arras (con o sin documento), el mismo sentido debería tener en las Instituciones, lo que evidentemente no ocurre, pues se dice allí expresamente... venditio celebrata est. Ergo: no parece verosímil que los compiladores tomaran la frase del Código para interpolarla (¡con otro sentido!) en las Instituciones.

Como hemos visto hasta aquí, el "celebrata est" de Instituta significa, respecto de la compraventa escrita, proyecto de compraventa (in scriptis celebranda) para ArangioRuiz ${ }^{94}$, quien reserva el "celebrata est" para la compraventa sine scriptis. Para Zulueta95, Marasinghe ${ }^{96}$, Lisowski ${ }^{97}$, Talamanca ${ }^{98}$ y Zimmermann ${ }^{99}$, más allá de los diferentes alcances que cada uno reconoce, "celebrata est" se refiere a la dación arral, a la manera de una operación producida en el contexto de un negocio o acuerdo preliminar no formalizado, referido exclusivamente a la compraventa cum scriptura. Para Thomas ${ }^{100}$, en cambio, "sive in scriptis sive sine scriptis" tanto en Código como en Instituta se refieren a la compraventa, pero en un contexto helenizante; haciendo, entonces, depender Instituta de Código, señala que "venditio celebrata est" se refiere a la compraventa in scriptis en formación, desde la perspectiva de la práctica oriental en materia de compraventa y, por tanto, de una manera desarticulada con el resto del sistema contractual justinianeo.

Otros autores como Watson ${ }^{101}$, Carusi ${ }^{102}$ y Gallo ${ }^{103}$ abandonan la necesidad de que "sive in scriptis sive sine scriptis" se refiera a lo mismo en Codex Iustiniani y en las Iustiniani Institutiones.

\footnotetext{
92 ThOMAs (1956) p. 276.

93 D'Ors (1958) p. 79.

94 (1956) p. 103.

95 ZULUETA (1945) p. 24.

96 MARASINGHE (1973) p. 352.

97 LISOWSKI (1950) pp. 75 ss.

98 TAlamanCA (1953) pp. 84 ss.

99 ZimMERMANN (1992) pp. 233 y 234.

100 ThOMAs (1956) pp. 277 ss.

101 WATSON (1959) p. 389.

102 CARUSi (1930) p. 554.

103 GaLlo (1964) pp. 39 y 40.
} 
Así Watson ${ }^{104}$, quien no objeta Código ${ }^{105}$, piensa que el "sive in scriptis sive sine scriptis" de Instituta, no aludía ni a la compraventa ni a las arras, sino simplemente al acuerdo imperfecto de celebrar la compraventa escrita (ya sea que el acuerdo tenga carácter puramente verbal o, si bien escrito, no se hayan completado todas las formalidades $\left.{ }^{106}\right)$; el texto diría: "para que el desistimiento pueda quedar impune, es necesario que no se hayan dado arras; si se han dado (hoc etenim subsecuto) antes de que las formalidades (de la venta) se hayan completado, háyase acordado la venta (que en definitiva debe hacerse por escrito) por (un precontrato) escrito o sin escritura, la parte que no cumplió pagará la pena de las arras".

Sin embargo, se debe destacar aquí la opinión de Carusi ${ }^{107}$. Este autor desconecta el problema textual respecto del momento en que técnicamente está celebrada la compraventa. Si, respecto de la compraventa escrita, la regla donde se inserta el "celebrata est" introdujera la especificación "sive in scriptis sive sine scriptis" en referencia a un mero proyecto, esto sería un absurdo. Ello, porque en el consenso in itinere es inconcebible la irretractabilidad, de forma que la mención a los preacuerdos escritos o no resulta del todo superflua. En cambio, en aquella parte del texto las arras aparecen como el factor que permite tal retractación. Asimismo, en el caso en cuestión, pensar que Código se refiere a las arras es una extrañeza exegético-crítica, pues no solo es curioso el "dare in scriptis... dare sine scriptis" que viene a proponer el texto, sino que resulta inconcebible que el compilador haya mencionado la distinción entre estas daciones, en circunstancias que la distinción entre compraventa sine scriptis e in scriptis es el paradigma en ambos textos ${ }^{108}$. El absurdo también se produciría al referir el "sive in scriptis sive sine scriptis" a una compraventa perfeccionada, porque la regla cobra importancia justamente ahora que se introdujo la compraventa cum scriptura. Para Carusi ${ }^{109}$, "venditio celebrata est" alude sencillamente a las dos formas de celebración de la compraventa, como si en realidad se dijera "celebratur fit" (sea celebrada), y no a que ambas se encuentren actualmente celebradas; es decir, en forma amplia el fragmento se refiere a las compraventas que "sean celebradas" sive sine scriptis sive in scriptis, aludiendo tan solo a las enumeración de las formas de celebración. Por esta vía, la frase no pugna con todos los momentos en que pueden presentarse las arras, ya antecediendo la compraventa escrita, ya contemporáneamente en ambas formas de compraventa, dándole carácter omnicomprensivo del tratamiento arral en Derecho justinianeo; "adimplere" en el texto podría aplicarse, en consecuencia, tanto al perfeccionamiento del escrito como al cumplimiento del contrato. Si bien estamos de acuerdo con la doctrina de fondo, ciertamente "celebrata est" no quiere decir "celebratur fit".

\footnotetext{
104 WATSON (1959) p. 389.

105 WATSON (1959) p. 385.

106 WATSON (1959) p. 387.

107 CARUSI (1930) p. 554.

108 CARUSi (1930) p. 553

109 CARUSI (1930) p. 554.
} 
Otra interpretación interesante es aportada por Gallo ${ }^{110}$, quien, en alguna medida, avanza más allá en la teoría de Lisowski gracias a que el profesor italiano da un nuevo significado al texto de Codex Iustiniani. Para Gallo, "celebrata est" también se debe entender en relación con ambas compraventas (por razones ciertamente distintas a las de Carusi): sin duda en la compraventa consensual y, también, respecto de la escrita, tanto en cuanto, mediando arras antes de la escrituración, queda en evidencia que las partes han mutado su voluntad de perseverar en la compraventa planificada in scriptis, transformándola en compraventa sine scriptis, si las arras se dan sin escritura, o en compraventa in scriptis ya perfecta, si las arras se dieron por escrito.

Ante todo, Gallo ha demostrado que en esta materia los principios generales adoptados por el Derecho oficial son la consensualidad y la obligatoriedad ${ }^{111}$, donde la excepción sería el pasaje de Código que nos preocupa ${ }^{112}$, referido a la compraventa escrita inspirada en el Derecho griego ${ }^{113}$. Ello tiene el mérito, para Nardi ${ }^{114}$, de no presentar la obra de Justiniano, salvo Novelas, como un bloque unitario a la hora de conectar ambos textos.

Este autor ve en Código la influencia de la partes Orientis, donde, en época prejustinianea, el contrato arral griego se encontraría configurado, por influencia de la compraventa consensual de Occidente $^{115}$, como un contrato preliminar (escrito o no escrito), lato sensu ${ }^{116}$, que engendraba la obligación de perfeccionar el contrato definitivo o de indemnizar en caso contrario ${ }^{117}$. Así, el tardo Derecho postclásico en Oriente habría permitido la supervivencia de la compraventa típicamente romana en la forma de contrato preliminar obligatorio ${ }^{118}$. En la norma transitoria de Código, referida a los prisca iura, Justiniano habría vetado el régimen anterior en el que, como indicábamos, una vez establecido el precio las partes debían perfeccionar el contrato o indemnizar, lo cual habría sido un principio aplicable a la compraventa en todas sus formas y no solo a la in scriptis ${ }^{19}$ justinianea. En consecuencia, Código habría dejado reducido el ámbito de las arras, en cuanto contrato preliminar, a la compraventa cum scriptura ${ }^{120}$, equiparada por Justiniano a la compraventa traslativa griega, en tanto que las arras se las concibe como el contrato arral griego ${ }^{121}$. El Emperador aprecia clara la diferencia entre compraventa y contrato arral ${ }^{122}$, como se deduce de la primera parte del texto, la que este autor considera espuria solo en lo que se refiere a la transacción ${ }^{123}$.

\footnotetext{
110 GALLO (1964) pp. 39 y 40.

111 GALLO (1964) pp. 41 ss. y 61 ss.

112 NARDI (1968) p. 217.

113 GALlo (1964) p. 45.

114 NARDI (1968) p. 215.

115 GALLO (1964) p. 15.

116 GALLO (1964) p. 25.

117 Gallo (1964) p. 18.

118 GALLO (1964) p. 16.

119 GALLO (1964) p. 14.

120 Gallo (1964) p. 58.

121 NARDI (1968) p. 215.

122 GALlO (1964) p. 56.

123 NARDI (1968) p. 218.
} 
Así como en Código la compraventa escrita y las arras habrían dejado sentir la influencia griega, paralelamente, en Instituta, se siguió el régimen romano ${ }^{124}$. De esta forma las arras ya no son un negocio autónomo sino un pactum adiectum de la compraventa que podía celebrarse in scriptis sive sine scriptis ${ }^{125}$, ya que en ambas permiten a las partes retractarse ${ }^{126}$ conminándoles una pena ${ }^{127}$. Las partes podían decidir si se sometían a la formalidad de la escritura o no, amparados en el principio de la más amplia libertad de forma ${ }^{128}$, de manera tal que, si optaban por la venta sine scriptis, las arras, además de la función penal que les ha atribuido Justiniano, retoman su clásica función de prueba del contrato ${ }^{129}$, y, en el otro extremo, si se optaba por la compraventa in scriptis (aquí lo interesante), igualmente funcionan como prueba, pues acreditan que las partes han desistido de su intención de perseverar en la formalidad de la escritura, de manera tal que la compraventa se perfeccionaba como resultado de reconducirse la cuestión a la compraventa sine scriptum ${ }^{130}$. En consecuencia, "celebrata est" no sería una aplicación incorrecta del latín desde esta perspectiva, sino el producto de haberse traducido en Instituta el contrato arral en un pactum adiectum, como se deduce de Paráfrasis 3,23 , pr. y Basílicas 22, 1, 76, donde la forma de perfeccionamiento aparece vinculada a la compraventa después de la introducción de la consensualidad por Justiniano ${ }^{131}$.

La verdad es que no podemos dar crédito a esta conjetura pues renuncia a resolver el problema de coherencia externa de los textos: en Codex Iustiniani las arras funcionarían como un contrato preliminar y en las Iustiniani Instituciones dicha función quedaría radicalmente excluida. Pensamos que si se trata de conocer el Derecho justinianeo, ello no se puede lograr, en principio, sino desde la contemplación del conjunto de la obra del Corpus Iuris, de manera que Código e Instituta deben interpretarse coordinadamente, no separados ni menos de forma opuesta ${ }^{132}$.

Sin embargo, tampoco su forma de salvar la coherencia interna de los textos resulta verosímil: desde ya, entender las arras prejustinianeas como un precontrato obligatorio no tiene base firme alguna, cayendo la explicación por la lectura del propio Código, pues una cosa es que Justiniano, en su intención oficial de instaurar la consensualidad, tenga que hacer concesiones a favor de la praxis jurídica vigente y otra, muy distinta, es que involucione desde un pretendido contrato preparatorio vinculante a un contrato arral griego, que solo indirectamente conducía a la celebración de la compraventa y que, como se ha observado ${ }^{133}$, en caso de no perfeccionarse la escritura no hay posibilidad de exigir la contraprestación. Más parece que la disposición transitoria de

\footnotetext{
124 GALLO (1964) p. 33.

125 Gallo (1964) p. 38.

126 GALLO (1964) p. 32.

127 NARDI (1968) p. 214.

128 GALLO (1964) p. 46.

129 GALlO (1964) p. 31.

130 GALLO (1964) pp. 39 y 40.

131 NARDi (1968) pp. 222 y 223.

132 CARUSI (1930) p. 551.

133 CARUSi (1930) p. 522
} 
Código, como lo indica Arangio-Ruiz ${ }^{134}$, sea un reflejo claro de la práctica prejustinianea de utilizar escrituras provisorias, la cual, en esta regulación del documento, ya no tendría lugar. La posición de Gallo no es en absoluto aceptable. Nos remitimos, también, a lo ya señalado en el párrafo anterior respecto de la mención de la distinción de arras escritas o no escritas, y a la "dación" escrita de estas.

Recapitulando, para Watson ${ }^{135}$, "celebrata est" alude nada más que a los acuerdos preparatorios de la compraventa escrita, los cuales podían ser "sive in scriptis sive sine scriptis", y los efectos de las arras en ese caso. Para Carusi ${ }^{136}$, en cambio, "celebrata est" debía leerse como "celebratur fit", de forma que "sive in scriptis sive sine scriptis" simplemente alude a las dos modalidades de compraventa sin especificar el momento de intervención de las arras; las que, en cualquier caso, podían intervenir antes de la compraventa escrita, o bien, después de perfeccionadas tanto la escrita como la no escrita. Para Gallo $^{137}$, "celebrata est" debe entenderse literalmente para ambas compraventas, tanto escritas como no escritas: respecto de la compraventa no escrita esto es obvio, pues no hay otra posibilidad en cuanto al momento de darse arras; en cuanto a la escrita, la sola dación de arras implicaba una renuncia a la formalidad, de modo que provocaba la perfección del contrato de compraventa, escrita, si las arras eran escritas, no escritas, si las arras no lo eran. En otras palabras, no podía haber arras entregadas antes de la perfección del contrato.

$\mathrm{Ni}$ el grupo de autores que busca dar un mismo significado al "sive in scriptis sive sine scriptis” en Código y en Instituta tanto como el grupo que no lo considera necesario, no resuelven realmente el problema del "venditio celebrata est". Además, un error común en todos estos autores es suponer que Instituta no puede contener una declaración más amplia que la de Código (relativo solo a un tipo de compraventa y solo en lo que respecta a su perfeccionamiento), cuestión que no tiene mayor fundamento.

\section{NUESTRA POSICIÓN}

Nos parece que la única forma de superar la dificultad es a través de la corrección histórico-crítica ${ }^{138}$, tal como lo ha propuesto D'Ors ${ }^{139}$ : se debe suponer que la frase "sive in scriptis sive sine scriptis" está en ambos textos relacionada con la venta; al igual, agregamos, que ya lo proponía Carusi ${ }^{140}$, en razón no solo de lo extraño que resulta en Código "dare in scriptis dare sine srciptis" en relación con las arras, sino también porque en ambos textos es la compraventa, y no las arras, el paradigma. Lo anterior conlleva a otra suposición más, cual es la primacía cronológica de Instituta sobre Código, pero, a

\footnotetext{
134 (1956) pp. 98 y 99.

135 WATSON (1959) p. 389.

136 CARUSi (1930) p. 554.

137 GALLO (1964) pp. 39 y 40.

138 FREZZA (1962) p. 307.

139 D'Ors (1955) pp. 149 ss.; SAMPER (en prensa).

140 CARUsi (1930) p. 553.
} 
diferencia de opiniones coincidentes en este punto, como las de Zulueta ${ }^{141}$ y Marasinghe ${ }^{142}$, en realidad son las Iustiniani Institutiones las que dan una explicación del verdadero sentido del Codex Iustiniani, y no a la inversa, como lo proponían en aquellos romanistas. La explicación sería la siguiente:

El año 528, Justiniano disciplinó la venta cum scriptura, o sea, aquella en que las partes retrasan su perfección al momento en que la escritura queda completa, y se dice que para este negocio que se prevé como futuro (superfacienda emptione), enunciándose el régimen del contrato arral para este caso ${ }^{143}$, las arras funcionan como "obligacionales" (llamadas penitenciales), de manera que las partes, antes de la realización del contrato, pueden desistirse con pérdida de las arras o su devolución doblada; pero no hay locus penitentiae una vez que la escritura está completa y la venta perfecta. Nada se decía de la venta sine scriptura, ni de la posibilidad de arras escritas o no escritas ${ }^{144}$; inclusive, como lo explica Schuster ${ }^{145}$, nos atreveríamos a suponer que no había ninguna alusión, en pr., a otro negocio distinto de la compraventa ${ }^{146}$ : ni arras ni permuta ni donación ni transacción ${ }^{147}$; todos ellos reunidos ahí por su carácter común de negocios traslativos, como lo ha dicho Arangio-Ruiz ${ }^{148}$.

Diría el texto simplemente: "Contractus venditionum... quos in scriptis fieri placuit"... Y el número 2: "Illud etiam adicientes, ut et in posterum, si quae arrhae superfacienda emtione cuiuscunque rei datae sunt..., licet non sit specialiter adiectum, quid super iisdem arrhis non procedente contractu fieri oporteat"...

En resumen, la primera versión de Código simplemente trataría de la solemnidad de la escritura y las arras dadas en medio tempore, en clara conexión con la configuración griega, todo ello acompañado de disposiciones transitorias destinadas a articular la disposición con el prisca iura, es decir, con el Derecho prejustinianeo donde se solían utilizar el contrato arral, para el caso de compraventas escritas, como antecedente de escrituras provisorias que creaban situaciones intermedias (como derechos de usufructo del comprador sobre la cosa, etc., pensadas para dar pie luego a figuras del tipo de la traditio brevi manus), destinadas a completarse cuando el precio su hubiera pagado ${ }^{149}$.

En el año 533 se redacta Instituta y, en el pasaje relativo a la forma de perfeccionarse la compraventa, vuelve Justiniano a enfrentarse con las arras. Pretende dar una visión sistemática ${ }^{150}$ que incluya el Derecho antiguo, de corte griego, todavía vigente

\footnotetext{
141 ZULETA (1945) p. 24.

142 Marasinghe (1973) p. 352.

143 FREZZA (1972) p. 307.

144 D'Ors (1955) p. 150.

145 SCHUSTER (1959) p. 45

146 FrEZZA (1962) p. 308.

147 Respecto de la mención a la transacción, hemos visto que usualmente se la tiene por interpolada. Así, GALLO (1964) p. 61; TALAMANCA (1963) p. 327 n. 14.

148 (1956) p. 98.

149 ARANGIO-RUiZ (1956) p. 100.

150 FREZZA (1962) p. 307.
} 
para las ventas sin escritura, el Derecho romano clásico y las reformas que él mismo introdujo cinco años antes, y viene a decir que si la venta es sin escritura, se aplica el Derecho romano clásico, esto es, el contrato se perfecciona por el consentimiento y las arras que se den serán confirmatorias; si la venta, en cambio, es escrita, se aplica el Derecho nuevo, y el contrato no se perfecciona hasta que se complete la escritura, por lo que las posibles arras se han de entender "obligacionales". Además, por medio de una declaración inédita, que incluye el Derecho oriental prejustinianeo, se establece que tanto si la venta es consensual como si es escrita (esto es, tanto si las arras son confirmatorias o son obligacionales), gracias a las arras habrá locus poenitendi, entremezclando la concepción de la práctica griega del contractum arrarum, con el carácter vinculante de la compraventa ya perfeccionada (celebrata est); carácter vinculante que está presente, evidentemente, en la compraventa no escrita, pero también, pese a retrasársele al momento de la solemnidad, en la escrita.

Ello se deduce no solo de "celebrata est" sino también de "adimplere", que puede referirse (con cierto relajo técnico del compilador), además de al cumplimiento del contrato, en el caso de la compraventa cum scriptura, a la confección completa del documento, como lo supone Carusi ${ }^{151}$. Habría en esta última parte de Instituta, como ya habíamos dicho, una doble extensión en el papel de las arras: respecto de la compraventa escrita, las arras previstas en Código como un negocio obligacional medio tempore entre el consenso y la solemnidad, pasan a funcionar como penitenciales, una vez perfeccionada la escritura; en relación a las compraventas no escritas, las arras agregan a su función confirmatoria la función llamada penitencial, que más bien se debe decir penal ${ }^{152}$

Esta (tercera) parte ubicada al final de las Iustiniani Institutiones podría corresponder con bastante seguridad a la práctica prejustinianea de unir a la dación de arras la lex commissoria, a la manera de una cláusula de estilo, que hasta habría llegado a subentenderse en todo acuerdo de compraventa, y que permitía confirmar a los contratantes la retractabilidad del consenso en su concepción helenística ${ }^{153}$.

Esta herencia del Derecho de Occidente sería una traducción del locus poenitendi que en el período clásico se lograba por medio de la lex commissoria que acompañaba a las arras en la compraventa consensual ${ }^{154}$. Sin embargo, existe una diferencia entre la lex commissoria y la datio arrarum, respecto del sistema justinianeo. De ahí que se aprecie con claridad su aparición como pactos autónomos el uno del otro en el Corpus Iuris, como lo señala Gallo ${ }^{155}$. Las diferencias apuntadas por D'Ors ${ }^{156}$ serían las siguientes:

\footnotetext{
151 CARUSI (1930) p. 554.

152 SAMPER (en prensa).

153 D'Ors (1958) pp. 80 y 81.

154 D'ORS (1955) p. 152.

155 GALLO (1964) p. 144.

156 D’Ors (1958) p. 80.
} 
1. El pacto comisorio es una facultad del vendedor, en cambio las arras justinianeas operan a favor de cualquiera de las partes.

2. El pacto comisorio es un accidentale negotii, en tanto el régimen justinianeo para la venta sine scriptis se presentaba como legal.

3. El pacto comisorio no opera automáticamente, sino a discreción del vendedor, de manera que este puede optar por el commissum o por el precio. En el régimen de las arras si bien existe la alternativa, a diferencia del pacto comisorio, la facultad de la parte perjudicada puede ser enervada si la otra parte se decidía a cumplir, en mora. En este último caso se refleja que en Justiniano, las arras de la compraventa consensual son confirmatorias, pues ambas partes pueden invocar la perfección del contrato.

Estamos de acuerdo con D’Ors ${ }^{157}$ cuando señala que en Instituta el “nihil... innovatus est" no entra en contradicción con esta interpretación, pues la compraventa sine scriptis sigue perfeccionándose por el solo consentimiento, lo que ha variado es la configuración de las arras que la acompañan, cosa muy distinta. Y, de otro lado, tampoco resulta grave que no se haya recordado las arras confirmatorias en la última parte de las Iustiniani Instituiones, pues la función confirmatoria subyace, en todo caso, cualquiera sea la función que desempeñen las arras.

El año 534 sobreviene la segunda y definitiva edición de Código ${ }^{158}$, y Justiniano pretende darle a nuestro pasaje una generalidad que no tenía en su origen: agrega en pr. una serie de negocios "traslativos de dominio", pero sin tener en cuenta que el problema de la ley era el de retrasar la perfección desde el momento del "consentimiento" al de la "solemnidad", e incluye actos que no presentan dicho problema por cuanto son "reales", tal como la permuta ${ }^{159}$, la donación ${ }^{160}$ y a las propias arras ${ }^{161}$.

157 D'Ors (1955) p. 150.

158 FrEZZA (1962) p. 308.

159 Las I. Inst. 3, 23, 2, hablan de la permuta como un "contrato particular", no así las Gai Inst. 3, 141. Aunque Justiniano le atribuya en este pasaje a Próculo tal calificación, parece indudable que no pertenece a este jurista. La permuta, el intercambio de cosa por cosa, es un negocio antiquísimo que, sin embargo, curiosamente en Roma no tuvo acogida como una institución jurídica específica. Este negocio solo fue amparado y sistematizado por el Derecho romano bizantino, gracias a la obra de Justiniano, quien negándole la absoluta independencia jurídica, lo incluye dentro de la categoría genérica de los contratos innominados, los que requieren de la ejecución de la prestación para hacer exigible la correlativa; en ese sentido la permuta es un negocio real, que requiere la dación de una de las cosa a intercambiar, por ello, Paulo cita a Pedio, en Paulo, 32 ad Ed., D. 19, 4, 1, 3, de la siguiente manera: "Ideoque Pedius ait alienam rem dantem 19.4.1.4 nullam contrahere permutationem".

160 GUZMÁn (1996) pp. 623 y 624. El año 323 se dispuso que ciertas donaciones fueran puestas por escrito (Frag. Vat. 249, C. Th. 8, 12, 1, C. I. 8, 53, 25; 5, 37, 21), ante testigos, y se inscribiera en un registro el instrumento (insinuación desde esta época), asimismo, la cosa fuera entregada materialmente al donatario, ante testigos. La falta de cualquiera de estas formalidades impedía la perfección de la donación, de tal manera que la donación reafirma, aunque en otro sentido, el carácter real de época clásica. Justiniano vuelve al régimen clásico de entrega material de la cosa donada, eso sí, en época clásica el acuerdo era un mero pactum, y por tanto no vinculante, en cambio ahora es un contrato, al que Iust. Inst. 2, 7, 2, declara a ejemplo de la constitución sobre la venta, puede ser perfeccionado tanto por escrito como sin escritura.

161 Ya hemos visto los argumentos de autores como CARUSI (1930) p. 553 (curiosidad exegética: ¿dare in scriptis... dare sine scriptum?); y, THOMAS (1956) pp. 257 y 267 (en un sistema que no conocía la consen- 
Además, deseoso de que el pasaje contenido en número 2, relativo a las arras, reflejara lo que se decía en Instituta, introduce la frase "sive in scriptis". Pero la interpolación se hizo sin muchos miramientos (seguramente por la distracción que produjo en los comisionados la inclusión de las arras escritas y sin escrituras en pr.), y en un lugar tal, que parecía que la distinción no se refería a la forma de la venta sino a la datio arrarum $^{162}$.

Advertimos, finalmente, que esta interpolación no podría ser desmentida, como se ha intentado por Thomas ${ }^{163}$, por otra constitución ${ }^{164}$ de Código, fechada el año 530, y por tanto anterior a la reedición que tratamos, y que se remite a nuestro pasaje de Código 4, 21, 17, en relación al "sive in scriptis sive sine scriptis", pues ella fue introducida teniendo a la vista Instituta, como lo ha demostrado D'Ors ${ }^{165}$.

En síntesis, el régimen arral justinianeo sería el siguiente:

(1) Las arras en un negocio consensual tienen función confirmatoria pero, además, por disposición legal y ya no por convención (lex commissoria), son penales (llamadas penitenciales), en cuanto sancionan pecuniariamente el arrepentimiento (factum poenitentiae), cumpliendo una función indemnizatoria por la no ejecución del contrato; ejecución que siempre pudo ser alternativamente exigida.

(2) Las arras en un negocio que debe ser reducido a escritura cumplen una función obligacional, fijando una pena para el caso de que alguna de las partes se arrepienta (ius poenitentiae), en el tiempo intermedio entre el consenso y el cumplimiento de la solemnidad, de su intención de llegar a perfeccionar el contrato. Luego de perfeccionado el contrato ("celebrata est" de Instituta), las arras pasan, al igual que en la venta no escrita, a fijar una pena a manera de indemnización por el incumplimiento (factum poenitentiae).

\section{COMENTARIOS FINALES}

En materia de arras, lo más notable es, sin duda, la introducción justinianea de las arras penitenciales. Ya los romanistas se han dado cuenta de los problemas que presenta la posibilidad que ellas dan de desistirse unilateralmente de un contrato ya perfecto $y$, por tanto, vinculante ${ }^{166}$.

sualidad es lógico que las arras tuviesen naturaleza real; si bien en la práctica también se escrituraban las arras, no es menos cierto que la sanción arral solo puede tener efecto si estas han sido efectivamente entregadas).

162 SAMPER (en prensa).

163 THOMAS (1956) p. 109

164 C. I. 4, 38, 15: "Quam decidentes censemus, cum huiusmodi conventio super venditione procedat 'quanti ille aestimaverit, sub hac condicione stare venditionem, ut, si quidem ipse qui nominatus est pretium definierit, omnimodo secundum eius aestimationem et pretia persolvi et venditionem ad effectum pervenire, sive in scriptis sive sine scriptis contractus celebretur, scilicet si huiusmodi pactum, cum in scriptis fuerit redactum, secundum nostrae legis definitionem per omnia completum et absolutum sit".

165 D’Ors (1960) pp. 325 ss.

166 SAMPER (en prensa). 
La mayor confusión, que se ha venido fraguando durante siglos, consiste en atribuir a las arras la virtud de permitir el arrepentimiento, en circunstancias que como lo enseña D'Ors ${ }^{167}$, respecto de las arras entregadas medio tempore en la venta cum scriptura justinianea- el carácter penitencial no proviene de las arras sino de la imperfección del contrato. Lo cierto que es que, en materia de arras obligacionales, el ius poenitendi no existe por el hecho de las arras, sino porque la venta escrita no se perfecciona mientras no se extienda la escritura. Resulta que, al contrario de lo que sugiere la dicha denominación, las arras vienen a imponer un límite a un ius poenitendi ya naturalmente existente, por cuanto establecen una pena por la fallida perfección del contrato. Por tanto su función nunca es penitencial, sino que, por el contrario, son una pena a la poenitentia ${ }^{168}$.

Las arras penitenciales vinculadas, por el contrario, a un contrato ya vinculante, claramente nos vienen heredadas desde un sistema, como el griego, muy distante de la consensualidad romana.

De hecho su recepción en el derecho moderno no fue, por así decir, por la puerta ancha, sino más bien por la ventana. En el Code se dejó sentir la influencia de Pothier ${ }^{169}$, quien admitía como penitenciales exclusivamente las arras pacto imperfecto data. Dicho de otra forma, no admitía más arras que las obligacionales. Esto determinó que la disposición relativa a tales arras se ubicara en sede de promesa de compraventa, en el artículo 1590, de forma que se vinculaban a la perfección del contrato prometido. Más tarde, solo por vía interpretativa se entendió que dichas arras igualmente podían acompañar un contrato perfecto ${ }^{170}$.

Estas lecturas "antipothierianas" del artículo 1590 del Code hacen descansar precisamente en las Iustiniani Institutiones 3, 23, pr. la posibilidad de aplicar directamente las arras penitenciales a la compraventa; así vino a refrendarse aquella institución que desde su núcleo histórico ha sido tan resistida por la romanística.

Tal como señala respecto de la nueva interpretación del artículo 1590 del Code, Afonso ${ }^{171}$, "lo que se quiere pues destacar con esta interpretación del pensamiento justinianeo es que la revocabilidad de un contrato de venta con pacto de arras no deriva de su propia debilidad jurídica, dada su imperfección, sino que, incluso habiendo el contrato alcanzado su perfección jurídica, podian las partes desistir libremente de la ejecución del mismo, siempre y cuando se sometieran a las consecuencias del pacto arral'.

Este giro doctrinal deja entrever serias incoherencias que hacen muy cuestionable la construcción de las arras penitenciales, la cual no se corresponde con los antecedentes históricos ni con las apreciaciones dogmáticas modernas. De hecho, parece suficientemente elocuente, para ilustrar la pobre opinión que la romanística tiene de ellas, citar la

167 D’ORS (1955) pp. 150 y 151.

168 CARUSi (1915) p. 305.

169 Pothier, (1847) p. 20 ss.

170 BONET (1947) p. 303.

171 AFONSO (1995) p. 191. 
opinión de Carusi ${ }^{172}$. Para este gran romanista italiano, las arras penitenciales justinianeas constituyen una "figura monstruosa por intrinseca contrariedad lógica y jurídica", pues las arras son, a la vez, el iter de la poenitentia y una pena al ejercicio de ese mismo arrepentimiento. Por ello, no se puede más que estar de acuerdo con Maynz ${ }^{173}$, cuando señala que las arras penitenciales son contrarias a todos los principios generales.

Un acuerdo sobre un contrato bilateral en que se agrega la cláusula de desistimiento equivale a decir: "estamos obligados, pero en cuanto alguna de las partes así ya no lo quiera, dejaremos de estarlo". Me parece que tal construcción es absurda si se quiere elevar una voluntad tan precaria a nivel de contrato ${ }^{174}$. Esta aspiración vulnera los principios más fundamentales del derecho contractual desde el momento que no parece que pueda nacer un contrato a partir de una convención en que falta la intención de obligarse ${ }^{175}$. Faltaría a esta declaración el requisito de "seriedad" que suele recordarse con relación a la oferta ${ }^{176}$-habitualmente de una manera que tal vez sea demasiado escolar-, pero que indudablemente integra toda declaración ${ }^{177}$ que pretenda ser vinculante ${ }^{178}$. De manera que, agregado el pacto de desistimiento, incluso determinada la cosa y el precio, no puede tenerse tal acuerdo por una compraventa perfecta, pues el "consentimiento" sobre el objeto contractual -que es un prius- no puede jurídicamente tener la consideración de tal ${ }^{179}$.

La perfección del contrato es un presupuesto de validez, de manera que la calificación de validez requiere como dato previo que este esté formado ${ }^{180}$ : una convención en las condiciones señaladas no puede ser considerada sino un trato preliminar ${ }^{181}$. Y no creo que en el caso de las arras penitenciales pueda salvarse la cuestión señalándose que hay convención porque, en todo caso, han nacido, y han sido queridas, las obligaciones propias de la dación de arras, lo que demostraría que el contrato en el que se insertan se ha perfeccionado y está desplegando su eficacia, pues, en atención al mismo carácter de cláusula accidental que generalmente se le reconoce a las arras -planteamiento que, en todo caso, no comparto-, el consentimiento tiene

\footnotetext{
172 CARUSi (1930) p. 509; CARUSi (1915) p. 304.

173 MAYNZ (1870) p. 401 n. 15.

174 SAVignY (s/d) pp. 221 y 222.

175 POTHIER (1844) pp. 80-81. Vid., LANDo (2000) pp. 137 ss. El artículo 2:101.1.(a) señala: “ $A$ contract is concluded if: the parties intend to be legally bound"...; y en el comentario se indica: "In order to be bound by a contract a party must have an intention to be legally bound"; agrega el artículo 2:102: "The intention of a party to be legally bound by contract is to be determined from the party's statements or conduct as they were reasonably understood by the other party".

176 Vid., con la bibliografía allí citada, MARTíneZ, (2000) pp. 38 ss.

177 MarTínez (2000) p. 75.

178 Resulta esclarecedor el antecedente que ofrecen las Partidas 5, 11, 2: "pregunta e respuesta ha menester que sea fecha en la promisión por palabras, e con entendimiento de se obligar".

179 LANDO (2000) p. 143: en el comentario al artículo 2:102, se indica: "Parties often make preliminary statements which precede the conclution of a contract but which do not indicate any intention to be morally or legally bound at that stage".

${ }^{180}$ LALAgUnA (1997) p. 113.

181 Vid. Alonso (1971) pp. 860 ss.; Lobato DE Blas (1976) p. 548.
} 
que recaer precisamente en los señalados elementos esenciales del contrato de compraventa y no solo en los accidentales.

De estas consideraciones se desprende que las arras penitenciales, de no haber sido incorporadas expresamente por los códigos modernos, no podrían ser incluidas voluntariamente por las partes en un contrato, pues la libertad contractual encuentra límites lógico-jurídicos en los aspectos fundamentales del sistema general de la contratación ${ }^{182}$.

\section{BIBLIOGRAFÍA CITADA}

Afonso, María Elvira (1995): Las Arras en la contratación (Barcelona, Bosch) 306 pp.

Albaladejo, Manuel (1996): Las arras en la jurisprudencia del Tribunal Supremo (Madrid, Editoriales de Derecho Reunidas) 121 pp.

ALONSO, Mariano (1971): La responsabilidad precontractual, RCDI 47 pp. 859-922.

ARANGIO-RUIZ, Vincenzo (1956): La compravendita in Diritto romano, 1 (Napoli, Casa Editrice Dott. Eugenio Jovene, segunda edición) 204 pp.

ARCHI, Gian Gualberto (1981): Scritti di Diritto Romano, 1 (Milano, Dott. A. Giuffrè Editore) $731 \mathrm{pp}$.

BONET, Francisco (1947): Comentario a la STS de 28 de diciembre de 1946, RDP 31: pp. 299-306.

CAnnata, Carlo Augusto (1996): Historia de la ciencia jurídica europea (traducc. Laura Gutiérrez-Masson Madrid, Tecnos) 242 pp.

CARUSI, Enrico (1915): Sul frammento L. 38 del Libro di Diritto siro romano, saggio di un metodo di essegesi comparativa in Diritto romano ed orientale, BIDR 28: pp. 261-328.

CARUSI, Enrico (1930): Sull'arra della vendita in diritto giustinianeo (a proposito di un recente studio), Studi in onore di Pietro Bonfante, 4 (Milano, Fratelli Treves Editori) pp. 503-564.

Carvajal, Patricio-Ignacio (2001): "El polimorfismo de las arras contractuales en el derecho civil moderno", Academia, Revista Jurídica Internacional, Universidad Veracruzana, 1-2: pp. 11-61.

CARVAJAL, Patricio-Ignacio (2005): "Las arras penitenciales en la tradición romanística del derecho civil español", Revista Chilena de Derecho, vol. 32, no 2: pp. 299-327.

CARVAJAL, Patricio-Ignacio (2003): Las arras penitenciales, en VV.AA.: El Dret Civil Català en el Context Europeu, coordinador: Àrea de Dret Civil (Girona, Universitat de Girona, Documenta Universitaria) pp. 231-264.

D’ORS, Álvaro (1958): “Arra reagitata”: sive in scriptis sive sine scriptis, IVRA 9: pp. 78-81.

D'ORS, Álvaro (1960): C. 4, 38, 15 (530), Interpolado por el mismo Justiniano, SDHI 26 pp. 325-329.

D’ORS, Álvaro (1997): Derecho Privado Romano (Pamplona, EUNSA, novena edición) $644 \mathrm{pp}$.

182 Albaladejo (1996) p. 42. 
D'ORS, Álvaro (1955): Las arras en la compraventa justinianea, IVRA 6: pp. 149-152.

DíEZ-PICAZO, Luis (1983): Fundamentos de Derecho Civil Patrimonial, 1 (Madrid, Tecnos, segunda edición) $889 \mathrm{pp}$.

FACHINEUS, Andrea (1609): Controversiarum juris, libri XIII (Lugduni, Sumptibus Horatii Cardon) col. 2495.

FreZZA, Paolo (1962): Le garanzie delle obligazioni, 1, (Padova, Casa Editrice Dott. Antonio Milani) 378 pp.

Gallo, Filippo (1964): Disposizioni di Giustiniano sulla forma della vendita (Torino, G. Giappichelli Editore) 173 pp.

GÓmez CAlero, Juan (1983): Contratos mercantiles con cláusula penal (Madrid, Editorial Civitas, segunda edición) 219 pp.

GuZMÁn Brito, Alejandro (1996): Derecho Privado Romano, 2 (Santiago, Ed. Jurídica de Chile) 790 pp.

Lalaguna, Enrique (1997): El contrato. Estructura, formación y eficacia (Valencia, Tirant lo Blanch) $241 \mathrm{pp}$.

LANDO, Ole (2000): Principles of european contract law (The Hage, Kluger Law International) $561 \mathrm{pp}$.

LISOWSKI, Zygmund (1950): "La prétendue contradiction entre" C. 4, 21, 17 et Inst. 3, 23, pr., RIDA, 5: pp. 73-77.

LOBATO De Blas, Jesús (1976): "Consideraciones sobre el concepto de tratos preliminares”, RGLJ 73: pp. 541-581.

MARASINGHE, M. Lakshman (1973): “Arra-not in dispute”, RIDA 20: pp. 349-353.

MARTíneZ, Eva (2000): La formación del contrato a través de la oferta y la aceptación, (Madrid, Marcial Pons) 151 pp.

MaYnZ, Charles (1870): Cours de droit romain, 2, (Paris Libraire Polytechnique D’Aug. Decq) $584 \mathrm{pp}$.

NARDI, Domenico (1968): "Giustiniano e la forma delle vendite", Labeo 14: pp. 214-224.

Pothier, Robert Joseph (1847): Traité de contrat de vente, 3 (Paris, Cosse et N. Delamotte) $536 \mathrm{pp}$.

Pothier, Robert Joseph (1844): Traité des obligations, en Ouvres Completes de Pothier, 1 (Paris, P. J. Langlois, Libraire; A. Durand, Libraire) p. 472.

SAMPER, F.: Las arras contractuales, en prensa.

SAVIGNY, F. (1874): Sistema del derecho romano actual, 2, (traducc. Jacinto Mecía y Manuel Poley Madrid, Góngora) 447 pp.

SCHUSTER, Werner (1959): Die Funktion der Arrha bei Justinian, Labeo 6 pp. 26-66.

TALAMANCA, Mario (1953): L'arra della compravendita in diritto greco e in diritto romano (Milano, Dott. A. Giuffrè Editore) 100 pp.

Talamanca, Mario (1963): Osservazioni sull'arra nel Diritto giustinianeo, Mélanges Philippe Meylan, 1 (Lausanne, Imprimera Centrale de Lausanne) pp. 325-336.

Thomas, J. A. C (1956): Arra in sale in Justinian's Law, TvR 24-1, pp. 253-278.

Trabucchi. Alberto (1990): Istituzioni di Diritto Civile, trigésimo primera ed. (Padova, Cedam) $871 \mathrm{pp}$. 
VINNIUS, Arnoldus (1767): Institutionum imperialium commentarius academicus et forenses, 2 (Lugduni, Sumptibus Fratrum de Tournes) pp. 571-998.

WATSON, Alan (1959): "Arra in the Law of Justinian”, RIDA 6: pp. 385-389.

ZimMERMANN, Reinhard (1992): The law of obligations. Roman fundations of the civilian tradition (Cape Town, Juta \& Co. Ltd.) 1241 pp.

Zulueta, Francis (1945): The roman law of sale (Oxford, Clarendon Press) 256 pp.

\section{JURISPRUDENCIA CITADA}

(Todas corresponden el Tribunal Supremo español y se encuentran en el Repertorio Aranzadi de Jurisprudencia).

STS, Sentencia 31. 7. 1992, Recurso núm. 795/1990, fundamento de derecho $6^{\circ}$.

STS, Sentencia 21. 6. 1994, núm. 633/1994, Recurso núm. 2180/1991, fundamento de derecho $5^{\circ}$.

STS, Sentencia 30. 12. 1995, núm. 1156/1995, Recurso núm. 2152/1992, fundamento de derecho $1^{\circ}$.

STS, Sentencia 4. 3. 1996, Recurso núm. 2723/1992, fundamento de derecho 4º.

STS, Sentencia 10. 2. 1997, núm. 65/1997, fundamento de derecho $2^{\circ}$.

STS, 22.9.99, núm 746/1999, fundamento de derecho $2^{\circ}$.

\section{NORMAS CITADAS}

Código Civil chileno.

art. 1554

art. 1801

art. 1803

Código de Comercio chileno

art. 107

art. 108

art. 109

Código Civil francés

art. 1590

Código Civil alemán

$\$ \$ 336$ a 338

Código suizo de las Obligaciones

arts. 160 a 163

Código Civil italiano

art. 1385 
Código Civil español

art. 1454

Código Civil peruano

art. 1477

art. 1478

art. 1479 .

art. 1480

art. 1483

Código de Comercio español

art. 343

Código Civil argentino

art. 1189.

Código de Comercio mexicano

art. 381

Código de Comercio argentino art. 475 